\title{
Research on Owner Project Management Maturity Model of Highway Construction Project
}

\author{
Yaxi Ren ${ }^{1, a)}$ and Yuanhua Jia ${ }^{1, b)}$ \\ ${ }^{1}$ School of traffic and transportation, Beijing Jiaotong University, Beijing 100044, China. \\ a)16120874@bjtu.edu.cn \\ b)yhjia@bjtu.edu.cn
}

\begin{abstract}
The level of highway construction project management is one of the factors that affect the success of the construction project, which is not only related to the investment benefit of the owner, but also related to the healthy development of the national economy. Aiming at the status quo of the project management of the owners of highway construction projects in China, this paper constructs a model of project management maturity in line with China's national conditions and studies the evaluation methods of the models. The model is validated by case study.
\end{abstract}

\section{INTRODUCTION}

In recent years, with the continuous promotion of international technical exchanges, the development and application of the project management maturity pattern have been more and more . Especially abroad, there have been many valuable project management maturity model, and they are widely used in foreign enterprise project management. Because the maturity model of highway construction project management is not yet introduced in the world, the geographical and cultural differences are different at home and abroad[1]. Therefore, when the project management maturity model is applied to the highway construction project, it needs to be localized. In order to solve this problem, this paper constructs the ower project management maturity model of highway construction project(HCP-OPM3).

The concept of Project Management Maturity Model proposed from the Capability Maturity Model (CMM) for software process[2], which was first developed by the Software Engineering Institute (SEI) of Carnegie Mellon University in November 1986. At present there are more than 30 project management maturity models. The OPM3, published by the U. S. Project Management Institute (PMI), is one of the widely respected[3]. In 2005, the UK government's department of commerce (OGC) released a portfolio, project set and project management maturity model (P3M3) to assess the organization's project management capabilities[4]. America's Capstone Planning \&control (PM) 2 model is a model for the project management maturity that is appropriate for its own project[5].

\section{THEORETICAL BASIS OF THE HCP-OPM3}

\section{Structure of the HCP-OPM3}

The project management maturity model, as a means of evaluating and improving the maturity of project management, has received extensive attention in engineering management circles. As shown in Fig.1, the elements include improved content and improved steps, and the organization can learn about its current state and its roadmap for improvement. The HCP-OPM3, which is studied in this paper, adopts two-dimensional model structure. One is owner project management maturity level(see Fig.2), and the other is the four life cycle and project management elements of the owner's project management. 


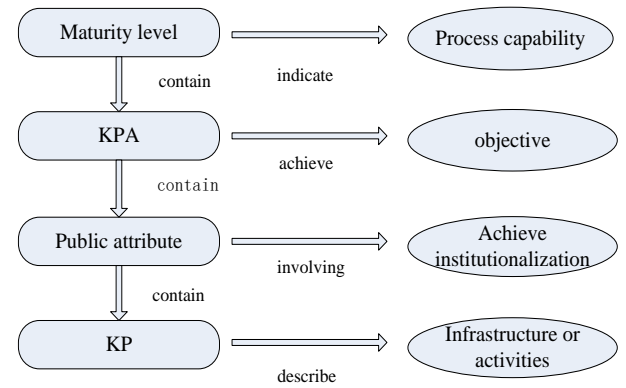

FIGURE 1. Model Internal Structure Diagram

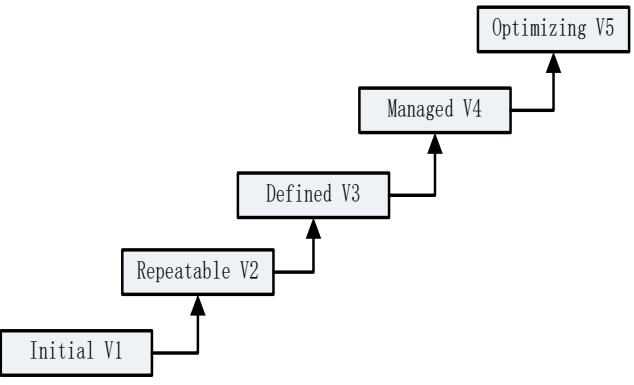

FIGURE 2. Maturity Level Demarcation

\section{Determination of the HCP-OPM3's Evaluation Index}

In this paper, the evaluation index system is a direct measure of the project management maturity, which includes the various life cycle of the owner highway construction projects. And it is also the foundation of index system of low grade division. Thus the determination of index system of rule layer is especially important. It is a complex problem to complete the four stages of all indicators to determine out. Because these indicators are different because of the stages and the evaluation objects. After every stage of the evaluation index system was determined, we should further to determine the next level of the index system until these indicators can be understood and accepted by the evaluation object in practical application. Based on the summary of the literature and the expert interviews, the evaluation index of the HCP-OPM3 is shown in TABLE 1.

TABLE 1. Evaluation Index System.

\begin{tabular}{ccc}
\hline First layer & Second layer & Third layer \\
\hline & Decision-making Stage U1 & Project Proposal U11 \\
& Preparation Stage U2 & Feasibility Study Report U12 \\
& Bidding Management U21 \\
Project & Procedures Settlement U22 \\
management & & Project Schedule Management U31 \\
maturity & Implementation Stage U3 & Project Quality Management U32 \\
& & Project Cost Management U33 \\
& & Project Contract Management U34 \\
& & Project Information Management U35 \\
& & Project Risk Management U36 \\
& Post Management Phase U4 & Project Safety Management U37 \\
& & Completion Inspection and Acceptance U41 \\
\hline
\end{tabular}

\section{Approach of the HCP-OPM3's Evaluation}

1. Analysis index weight by analytic hierarchy process(AHP).[6]

At first, we should determine the logical order of index evaluation, and then analysis the relationship between the indexes. The judgment matrix can be obtained by comparing the importance of any two indexes under a certain hierarchy.

For the integrated judgment matrix, the upper layer weight matrix is:

$$
W_{A}^{T}=\left[W_{1}, W_{2}, \cdots W_{i}\right]^{T}
$$

The consistency check formula is:

$$
C I=\frac{\lambda_{\max }(A)-n}{n-1}
$$

2.The determination of the fuzzy judgment matrix[7] 
Through the questionnaire, the evaluation of various indicators can be obtained by the professionals. By sorting and analyzing, we can get the membership of each index to the grade "y".

The membership calculation formula is:

$$
\mathrm{r}_{\mathrm{ijky}}=\mathrm{V}_{\mathrm{ijky}} / \sum_{\mathrm{y}=1}^{5} \mathrm{~V}_{\mathrm{ijky}}
$$

Where $V_{i j k y}$ is the number of the class of $V_{y} ; r_{i j k y}$ is the membershipof indicator $U_{i j k}$ which is aimed at grade $y$.

3.Calculate the value of comprehensive evaluation.

Based on the analysis of the index membership, the evaluation matrix $B_{i j}$ of each index is obtained. And according to the following formula, the evaluation vector $\mathrm{B}_{\mathrm{ij}}$ of the single index is calculated .

$$
B_{i j}=A_{i j} \bullet R_{i j}=\left(\begin{array}{llll}
a_{i j 1} & a_{i j 2} & \ldots & a_{i j k}
\end{array}\right) \times\left(\begin{array}{ccccc}
r_{i j 11} & r_{i j 12} & r_{i j 13} & r_{i j 14} & r_{i j 15} \\
r_{i j 21} & r_{i j 22} & r_{i j 23} & r_{i j 24} & r_{i j 25} \\
\ldots & \ldots & \ldots & \ldots & \ldots \\
r_{i j k 1} & r_{i j k 2} & r_{i j k 3} & r_{i j k 4} & r_{i j k 5}
\end{array}\right)=\left(\begin{array}{llll}
b_{i j 1} & b_{i j 2} & \ldots & b_{i j 5}
\end{array}\right)
$$

The resulting evaluation result $B=\left(\begin{array}{llllll}b_{1} & b_{2} & b_{3} & b_{4} & b_{5}\end{array}\right)$ is the result of the fuzzy comprehensive evaluation of the passenger satisfaction. In the calculation process, the effect of the factor layer index was also considered as well as the impact of category layer indexes on satisfaction. Therefore, the result of this evaluation method is the comprehensive reflection of all levels of evaluation.

The calculation of composite indexes is based on the following formula:

$$
U=B \times C^{T}
$$

Where $\mathrm{U}$ is the value of the management maturity of the project owners of highway construction projects; $\mathrm{B}$ is the final integrated evaluation vector; $C$ is a row vector matrix, such as $C=(1,2,3,4,5)$. Among them, 1 represents very dissatisfied; 2 represents less satisfaction; 3 basic satisfaction; 4 representative satisfied; 5 representative very satisfied.

\section{APPLIED RESEARCH}

Now with a highway construction project as an example, we evaluate the owner's project management maturity level.On the premise of 10 experts to visit, we can get the weight of each index in the index system by using AHP to analyze the evaluation results of experts. Through the investigation of the 10 middle and high level project managers

\begin{tabular}{|c|c|c|}
\hline Indexs & Calculation Process $\left(U=B \times C^{T}\right)$ & Results \\
\hline U11 & $\left(\begin{array}{lllll}0 & 0 & 0.4 & 0.6 & 0\end{array}\right) \times\left(\begin{array}{lllll}1 & 2 & 3 & 4 & 5\end{array}\right)^{\mathrm{T}}$ & 3.60 \\
\hline U12 & $\left(\begin{array}{lllll}0 & 0.2 & 0.6 & 0.2 & 0\end{array}\right) \times\left(\begin{array}{lllll}1 & 2 & 3 & 4 & 5\end{array}\right)^{\mathrm{T}}$ & 3.00 \\
\hline U21 & $\left(\begin{array}{lllll}0 & 0.2715 & 0.3 & 0.3117 & 0.1168\end{array}\right) \times\left(\begin{array}{lllll}1 & 2 & 3 & 4 & 5\end{array}\right)^{\mathrm{T}}$ & 3.27 \\
\hline $\mathrm{U} 22$ & $\left(\begin{array}{lllll}0 & 0 & 0 & 0.5 & 0.5\end{array}\right) \times\left(\begin{array}{lllll}1 & 2 & 3 & 4 & 5\end{array}\right)^{\mathrm{T}}$ & 4.50 \\
\hline U31 & $\left(\begin{array}{lllll}0 & 0 & 0.4275 & 0.5724 & 0\end{array}\right) \times\left(\begin{array}{lllll}1 & 2 & 3 & 4 & 5\end{array}\right)^{\mathrm{T}}$ & 3.57 \\
\hline U32 & $\left(\begin{array}{lllll}0 & 0 & 0.3776 & 0.5891 & 0.0332\end{array}\right) \times\left(\begin{array}{lllll}1 & 2 & 3 & 4 & 5\end{array}\right)^{\mathrm{T}}$ & 3.66 \\
\hline U33 & $\left(\begin{array}{lllll}0 & 0 & 0.1223 & 0.8393 & 0.0383\end{array}\right) \times\left(\begin{array}{lllll}1 & 2 & 3 & 4 & 5\end{array}\right)^{\mathrm{T}}$ & 3.92 \\
\hline U34 & $\left(\begin{array}{lllll}0 & 0.0179 & 0.2996 & 0.6825 & 0\end{array}\right) \times\left(\begin{array}{lllll}1 & 2 & 3 & 4 & 5\end{array}\right)^{\mathrm{T}}$ & 3.66 \\
\hline U35 & $\left(\begin{array}{lllll}0 & 0.1554 & 0.4102 & 0.4344 & 0\end{array}\right) \times\left(\begin{array}{lllll}1 & 2 & 3 & 4 & 5\end{array}\right)^{\mathrm{T}}$ & 3.28 \\
\hline U36 & $\left(\begin{array}{llllll}0 & 0 & 0.4667 & 0.5333 & 0\end{array}\right) \times\left(\begin{array}{lllll}1 & 2 & 3 & 4 & 5\end{array}\right)^{\mathrm{T}}$ & 3.53 \\
\hline U37 & $\left(\begin{array}{lllll}0 & 0.025 & 0.625 & 0.35 & 0\end{array}\right) \times\left(\begin{array}{lllll}1 & 2 & 3 & 4 & 5\end{array}\right)^{\mathrm{T}}$ & 3.33 \\
\hline U38 & $\left(\begin{array}{lllll}0 & 0.1334 & 0.4364 & 0.43019 & 0\end{array}\right) \times\left(\begin{array}{lllll}1 & 2 & 3 & 4 & 5\end{array}\right)^{\mathrm{T}}$ & 3.30 \\
\hline U41 & 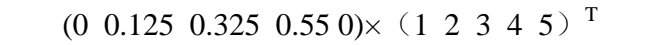 & 3.43 \\
\hline U42 & $\left(\begin{array}{lllll}0 & 0.1 & 0.4 & 0.5 & 0\end{array}\right) \times\left(\begin{array}{lllll}1 & 2 & 3 & 4 & 5\end{array}\right)^{\mathrm{T}}$ & 3.4 \\
\hline
\end{tabular}
of the enterprise, the fuzzy membership degree of each index is obtained. The resulting fuzzy comprehensive evaluation results are shown in Table 1 and Table 2. 
TABLE 2. Fuzzy Evaluation Result of Each Index Element of the Second Layer.

\begin{tabular}{|c|c|c|}
\hline Indexs & Calculation Process $\left(\mathbf{U}=\mathbf{B} \times \mathbf{C}^{\mathbf{T}}\right)$ & Results \\
\hline $\mathrm{U} 1$ & $\left(\begin{array}{lllll}0 & 0.15 & 0.55 & 0.3 & 0\end{array}\right) \times\left(\begin{array}{lllll}1 & 2 & 3 & 4 & 5\end{array}\right)^{\mathrm{T}}$ & 3.15 \\
\hline $\mathrm{U} 2$ & $\left(\begin{array}{lllll}0 & 0.2262 & 0.25 & 0.343 & 0.1807\end{array}\right) \times\left(\begin{array}{lllll}1 & 2 & 3 & 4 & 5\end{array}\right)^{\mathrm{T}}$ & 3.48 \\
\hline U3 & $\left(\begin{array}{lllll}0 & 0.0131 & 0.3594 & 0.6122 & 0.0153\end{array}\right) \times\left(\begin{array}{lllll}1 & 2 & 3 & 4 & 5\end{array}\right)^{\mathrm{T}}$ & 3.63 \\
\hline $\mathrm{U} 4$ & 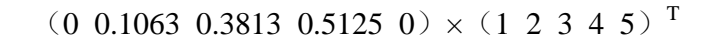 & 3.41 \\
\hline
\end{tabular}

Final maturity evaluation results: $\mathrm{U}=\mathrm{B} \times=\left(\begin{array}{lllll}0 & 0.0716 & 0.4087 & 0.5005 & 0.0192\end{array}\right) \times\left(\begin{array}{lllll}1 & 2 & 3 & 4 & 5\end{array}\right) \mathrm{T}=3.47$

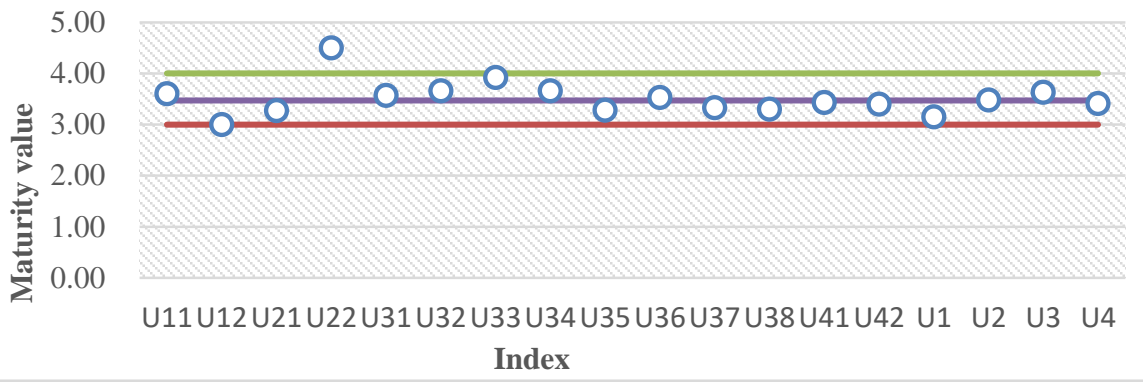

FIGURE 3. Result analysis.

Based on the results of TABLE 2, TABLE 3 and Fig.3, we can get the following conclusion: The project management maturity of the owner is exactly between the Defined level and the Managed level, which is in the middle of the maturity level. These data indicate that the highway construction project management level of the ower is not the best, and all aspects need to continue to improve. The TABLE 2 and TABLE 3 show that the maturity values of each index are mostly between 3-4 points, comprehensive maturity evaluation results is 3.47 , so the index which is below 3.47 need to focus on.

\section{CONCLUSION}

This paper studies the construction of the HCP-OPM3. Based on analysis of the domestic and foreign project management maturity model, we find that there are many obstacles for domestic scholar to apply foreign research results directly, because the enterprise culture inside and outside is different from the market economy environment. However, we can't directly apply the research in this area because of industry restrictions and research areas. Therefore, before the establishment of the model, I first solve the problem of localization and specialization of the model. The fuzzy comprehensive evaluation method is used to visualize the project management maturity model. Although this paper has improved the management maturity model of highway construction project owners, there are still disadvantages. In a word, a case study analysis of success does not mean success.

\section{ACKNOWLEDGMENTS}

This work was financially supported by T16100030 fund.

\section{REFERENCES}

1. Guangshe Jia, Shouhua Yang, Li Cao. Based on the property of large construction engineering project management maturity model research [J]. Journal of project management technology, 2008, 6 (7) : 60-64.

2. Carnegie Mellon University. Capability Maturity Model. Retrieved:June 25, 2007 from:http://www. sei. emu. Edu

3. Capstone Planning\&Control Inc. Project Management Maturity. from:http://www.capstone.com

4. OGC. Project management maturity model (PMMM). OGC-Release Version 5.0, 2002, 10.

5. Project Management Institute (PMI). Organizational Project Management Maturity Model Knowledge Foundation(OPM3)[M].Newtown Square:PMI,2003:149-169.

6. Bingjiang Zhang. Analytic hierarchy process and its application case [M]. Beijing: electronic industry press, 2014:10-57. 
7. Zhinong Jin, Duanmei Li, Ying Jin, Ni Xiong. The performance evaluation index of local research institutions and their weight calculations. Science and technology management research. 2009 (12) : 103-106. 